\title{
Ultrastructural Studies on the Nuclear Changes in Insufficient-stimulated Eggs of the Sea Urchin
}

\author{
Norihiko Uto and Junzo Tsukahara ${ }^{1}$ \\ Sugashima Marine Biological Station, Nagoya University, \\ Toba-shi, Mie-ken, 517 Japan
}

Received May 17, 1976

On succeeding morphological changes after the contact of the sperm to the egg surface in the sea urchin, many investigators have studied ultramicroscopically. Longo and Anderson (1968) have shown in detail the description on the fine structure in these serial fertilization events in Arbacia punctulata.

On the other hand, artificial parthenogenesis has been investigated to analyze the events associated with fertilization. Sachs and Anderson (1970) have studied on the ultrastructural changes in parthenogenetically activated eggs with hypertonic sea water. They have reported that artificially activated eggs undergo the cortical reaction as in the case of inseminated eggs and that cortical granules are released at random loci at the surface of the egg and result in spaces separated by large cytoplasmic projections.

It has been shown by Uto and Sugiyama (1969), and Nakashima and Sugiyama (1969) that a single insufficient stimulation with butyric acid evokes invisible metabolic changes, such as synthesis of DNA and protein, without breakdown of the cortical granules and formation of the fertilization membrane. Summation of the insufficient stimulation induces morphological changes of the nucleus, such as the swelling and migration toward the egg center, and further, cleavage of some eggs (Kojima 1969).

It is of interest to investigate the ultrastructural changes and the loci of DNA synthesis in the nucleus of the insufficiently activated egg, and to compare with that occurred in normal fertilization.

In the present study, we have made electron microscopic observation to study on the DNA synthesis and nuclear changes of the eggs which are repeatedly activated by an insufficient treatment with butyric acid.

\section{Material and method}

The egg of the sea urchin, Hemicentrotus pulcherrimus was used as a material. After the eggs were washed well with filtered sea water, insufficient activation was carried out as follows. Unfertilized eggs were treated with $4 \%$ butyric acid $(4 \mathrm{ml}$ $0.1 \mathrm{~N}$ butyric acid $+96 \mathrm{ml}$ sea water), which is a maximal time-length with an induction of visible cortical changes. This insufficient stimulation was applied repeatedly

1 Present address: Department of Biology, Colledge of Liberal Arts, Saitama University, Shimo-ookubo, Urawa-shi, Saitama-ken, 338 Japan. 
3 times at 4 min intervals, and finally, the eggs were washed with sea water. Such eggs were called "the eggs repeatedly stimulated with insufficient butyric acid treatment (RIS eggs)". The RIS eggs were incubated in a flat dish with filtered sea water at $18-20^{\circ} \mathrm{C}$.

After keeping of them in sea water for 2, 4, 6 and $8 \mathrm{hr}$, the eggs were fixed with $2.5 \%$ glutaraldehyde in sea water $\left(\mathrm{pH} \mathrm{7.4)}\right.$ for $1 \mathrm{hr}$ at $4^{\circ} \mathrm{C}$. They were then rinsed several times with sea water and postfixed with $1 \% \mathrm{OsO}_{4}$ in sea water $(\mathrm{pH} 7.2)$ for $1 \mathrm{hr}$ at $0^{\circ} \mathrm{C}$. Following dehydration by an ethanol series, specimens were embedded in Epon 812. Thin sections were made on a Porter-Blum ultramicrotome and stained with a saturated solution of uranyl acetate for $1 \mathrm{hr}$. After washing with distilled water, they were stained with a lead nitrate solution for $30 \mathrm{sec}$. Observations were made with a Hitachi HU-11ES electron microscope. At the same time, thick sections for light microscopy were prepared and stained with $1 \%$ toluidine blue. Paraffine sections were prepared as follows. The RIS eggs were fixed with a Bouin's fixative at the appropriate period, dehydrated with alcohol and embedded in paraffin. Sections were prepared $7 \mu$ thickness and stained with haematoxylin.

For autoradiography, the RIS eggs were put into the medium containing ${ }^{3} \mathrm{H}$-thymidine $\left({ }^{3} \mathrm{H}-\mathrm{TdR}\right)$ (Specific activity $5.0 \mathrm{Ci} / \mathrm{mM}$, at a concentration of $5 \mu \mathrm{Ci} / \mathrm{ml}$ ). They were incubated with occasional agitation for $5 \mathrm{hr}$ at $18-20^{\circ} \mathrm{C}$. As the autoradiography for light microscopic examination, specimens on the slides were coated with Sakura NR-M2 emulsion and stored in the light tight slide box for 14 days. For electron microscopic autoradiography, Sakura NR-H2 emulsion was applied by the wire loop method. After the exposure for 4-5 weeks, the autoradiographs were developed with the developer, Konidol X, and then fixed, followed by washing and staining.

In order to assay the effects of actinomycin $\mathrm{D}$ and cycloheximide on nuclear changes, these antibiotics were added to 5 aliquots of the RIS egg suspension at a final concentration of 50,100 and $200 \mu \mathrm{g} / \mathrm{ml}$ for actinomycin $\mathrm{D}$, and 200 and $400 \mu \mathrm{g} / \mathrm{ml}$ for cycloheximide. Afterward, the nuclear diameter of the RIS eggs in each batch was measured at intervals of $1 \mathrm{hr}$ for $7 \mathrm{hr}$. Seven hr later, a part of each aliquot was taken as a specimen for electron microscopy.

For the digestion experiment with Pronase, a kind of protease, the RIS eggs fixed with $2.5 \%$ glutaraldehyde for 40 min were washed well with $0.01 \mathrm{M}$ Tris buffer solution (pH 6.9) and then digested for $1 \mathrm{hr}$ at $37^{\circ} \mathrm{C}$ with Pronase $(1 \mathrm{mg} / \mathrm{ml})$ dissolved in $0.01 \mathrm{M}$ Tris solution (pH 6.9) containing $0.03 \mathrm{M} \mathrm{MgSO}_{4}$. These eggs washed with the buffer solution and post-fixed with $1 \% \mathrm{OsO}_{4}$. As controls for the experiment, a part of the RIS eggs was incubated in Tris buffer solution without the enzyme.

Results

Observation with the light microscope

In the RIS eggs (see the section of "Material and method"), the nuclei gradually swell and attain to about $40 \mu$ in diameter $8 \mathrm{hr}$ later.

From the observation on thick sections of these eggs embedded in Epon, the toluidine blue positive granules are found on the marginal zone of the nucleus 
(Fig. 1a), though they are scarcely seen in unfertilized eggs (Fig. 1b). These granules exist 10 to 20 in number per one optical section of a nucleus.

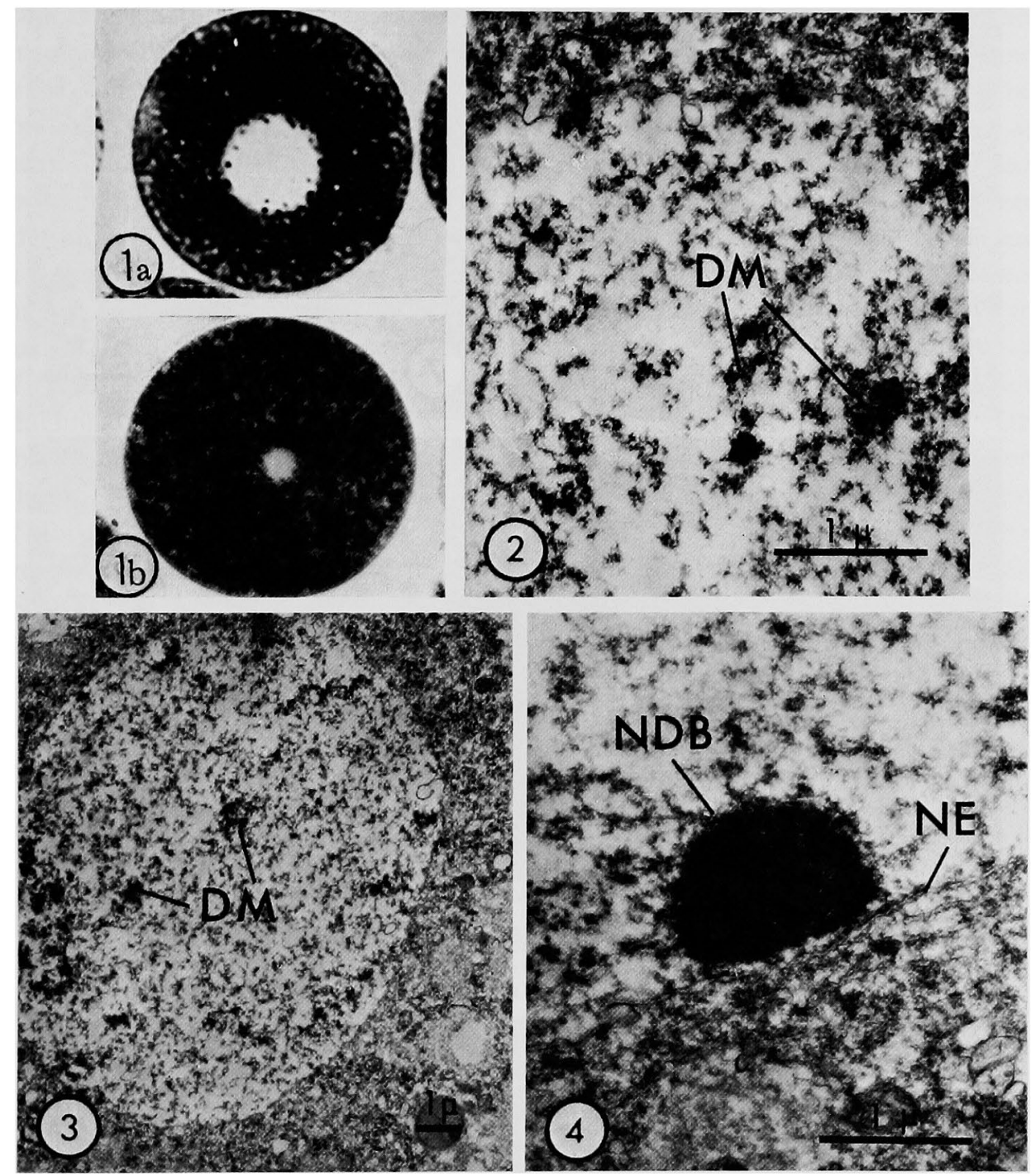

Figs. 1-4. 1. Nuclear appearance of the eggs repeatedly stimulated with insufficient butyric acid treatment (RIS eggs) and unfertilized eggs. a, the RIS egg which incubated for $8 \mathrm{hr}$ at $18-20^{\circ} \mathrm{C}$. Thick section prepared by Epon embedding was stained with toluidine blue. The toluidin blue positive granules are seen in the nucleus. In marginal zone of the nucleus, they are present at the rate of 10 to 20 in number per cross section. b, an unfertilized egg as a control. No granules are seen. 2-4. The RIS egg kept in sea water for 2, 4 and $6 \mathrm{hr}$ after insufficient activation. 2, electron dense material (DM) appears scatteringly within a nucleoplasm after $2 \mathrm{hr} . \quad \times 18,000 . \quad 3$, many DMs more condense and gather forming compact masses after $4 \mathrm{hr} . \quad \times 4,800.4$, DM becomes spherical nuclear dense body (NDB) after $6 \mathrm{hr}$. Most of them adjoin the nuclear envelope (NE). $\times 18,000$. 

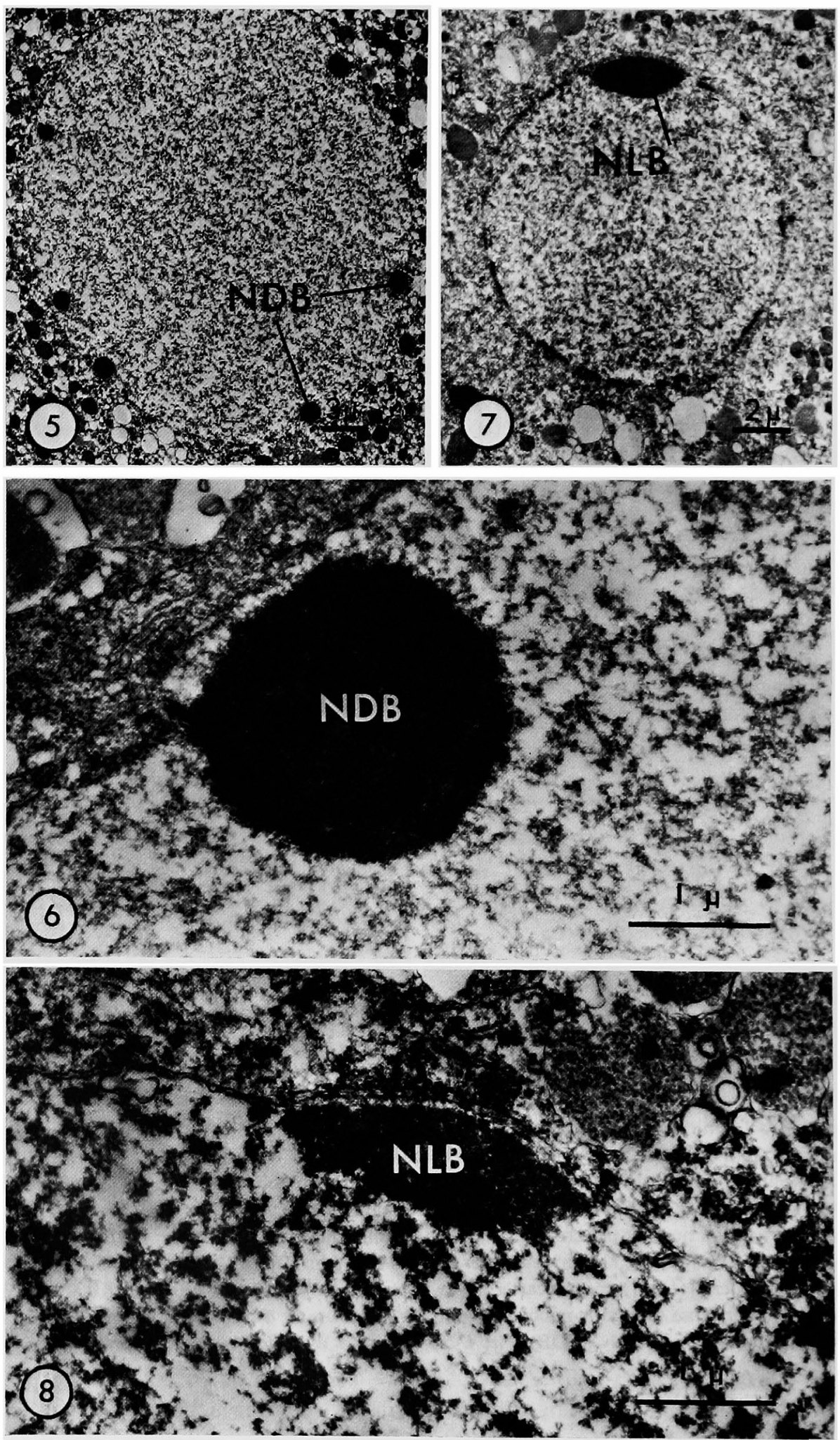


\section{Observation with the electron microscope}

Intranuclear changes proceeding with the time sequence in the RIS eggs were investigated. About $2 \mathrm{hr}$ after final activation, electron dense materials appear scatteringly and locate at some distance from the nuclear envelope (Fig. 2). Their structures are composed of fibrous and granulous materials as the same appearance as the condensed chromatin threads. Approximately $4 \mathrm{hr}$ later, these dense materials condense still more and gather forming the compact masses (Fig. 3). They are seemed to migrate and locate near the nuclear envelope. By $6 \mathrm{hr}$, a number of such dense materials are settled and observed as spherical bodies (Fig. 4). Most of them adjoint to the nuclear envelope. Afterward, they increase gradually in number and in volume, according as the time elapses. Fig. 5 shows the accomplished appearance, that is, some spherical intranuclear bodies are seen at the peripheral zone of the nucleus. This body is designated as the "nuclear dense body (NDB)". Formation of these bodies begins at about $2 \mathrm{hr}$ and accomplishes for $6-8 \mathrm{hr}$ after activation. Magnified figure of the NDB formed at $8 \mathrm{hr}$ was shown in Fig. 6. The NDBs observed in the RIS eggs are more or less spherical in shape (1.5-2 $\mu$ in diameter). They have a texture consisting of a large number of granular components and of fibrous components. On the contrary, in unfertilized eggs, a very few entities are observed in contact with the nuclear envelope, they may be "nucleolus-like bodies (NLB)" (Fig. 7), which will become to nucleolus at the early gastrula stage. They are lenticular in shape. The axes of the major and minor direction are about $2 \mu$ and $1 \mu$, respectively. The NLBs are composed of homogeneous chromatin particles. The region of the nuclear envelope adjacent to NLB thickens (Fig. 8) and shows an annulate-appearance, as compared with the NDB-adhering region of the nuclear envelope. The region is seemed an active site interacting between nucleus and cytoplasm.

\section{Autoradiographic examination with the electron microscope}

Previously, thymidine incorporation into the nuclei of the insufficiently activated eggs of Anthocidaris crassispina was found by the light microscopic autoradiography (Uto and Sugiyama 1969). The present experiment was designated to know the loci of DNA synthesis in the nucleus of the RIS eggs. The RIS eggs were exposed to ${ }^{3} \mathrm{H}-\mathrm{TdR}$ immediately after activation, and fixed $8 \mathrm{hr}$ later. In the progressive stage of the eggs, there is a significant increase of incorporation of the radioisotope into the nuclei. As shown in Fig. 9a, the high grain density is demonstrated at the periphery of the nucleus. The result agrees with the previous report of Uto and Sugiyama (1969).

At the early stage in the formation of the NDB, dense materials, which seem to result from chromatin condensation, are widely scattered in the nucleus. As was

Figs. 5-8. 5, the RIS egg kept in sea water for $8 \mathrm{hr}$. Many NDBs are seen at the inner surface of the nuclear envelope. $\times 2,000.6$, appearance of the nuclear dense body (NDB). NDB is almost spherical in shape. $\times 20,000$. 7, electron micrograph of a nucleus of the unfertilized egg left for $8 \mathrm{hr}$ in sea water. The lenticular nucleolus-like body (NLB) is observed in contact with the nuclear envelope. $\times 4,000$. 8 , appearance of the nucleolus-like body (NLB). NLB is lenticular in shape. The region of the nuclear envelope adjacent to NLB thickens and shows an annulate-appearance. 
shown in the autoradiographic feature (Fig. 9b), many silver grains are found on these dense materials. At the following stage, they gather and get to make masses in several places. Fig. $9 \mathrm{c}$ shows the feature approached to this stage. In the
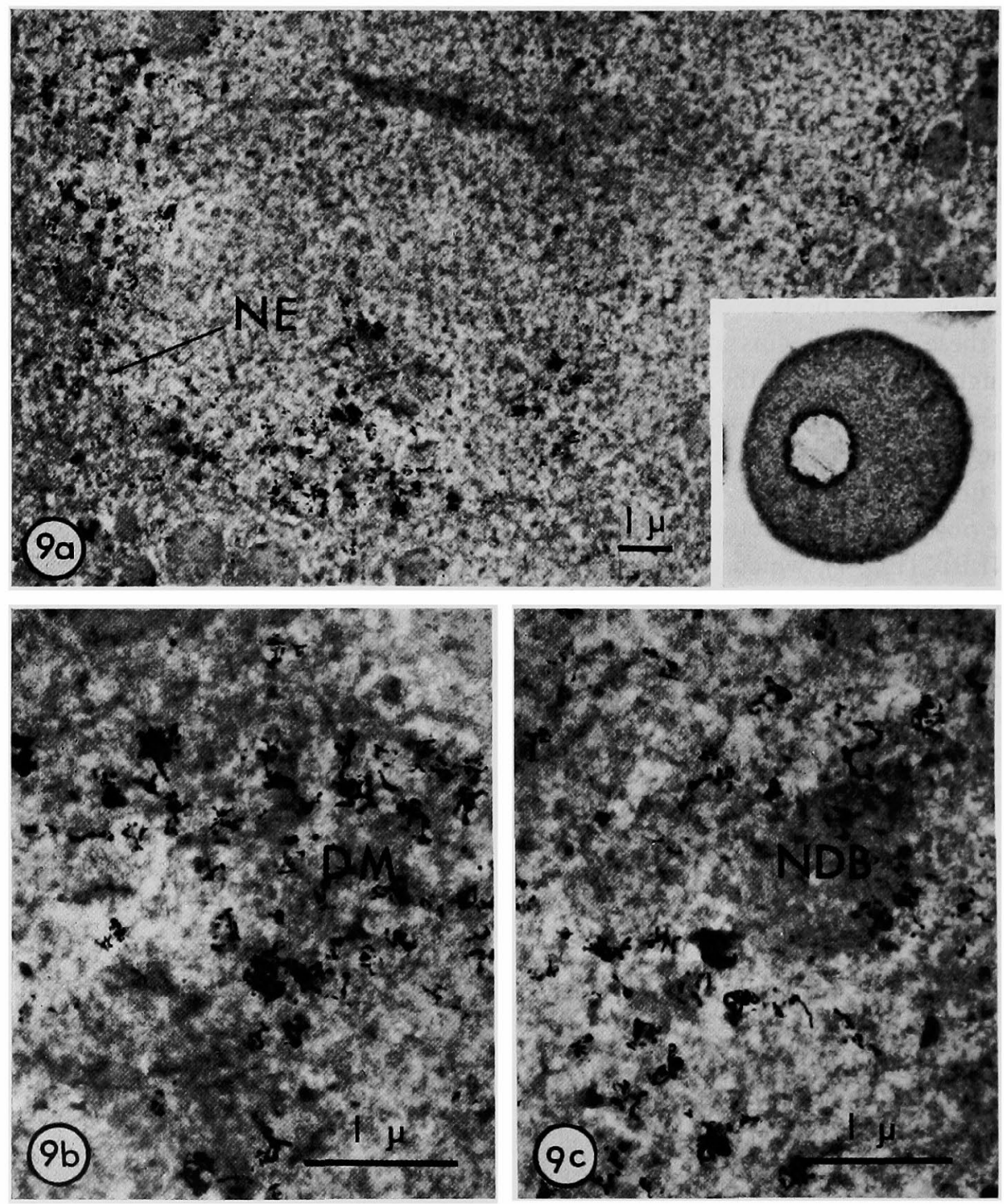

Fig. 9a, b and c. Electron and light (insert) microscope autoradiograms of the RIS egg labeled in sea water containing ${ }^{3} \mathrm{H}-\mathrm{TdR}(5 \mu \mathrm{Ci} / \mathrm{ml})$ for $5 \mathrm{hr}$. a, showing that developed grains are observed near the nuclear envelope (NE). $\quad \times 6,400 . \quad b$, on the dense materials (DM). $\times 18,000 . \quad c$, on the nuclear dense body (NDB) formed completely. $\times 18,000$.

process of formation of the DNB, silver grains are observed on the final form of the NDB and on the neighbouring dense materials. This result indicated that dense materials play a role in formation of the NDB. In general, DNA synthesis takes place just before chromatin condensation. In relation to the site of DNA 
synthesis, it has been reported the synthesis occurs initially on the nuclear envelope (Comings and Kakefuda 1968). The present experiment confirmed their result. And also, the synthesis was detected in the dense materials which seems to be consist of condensed chromatin and other components.

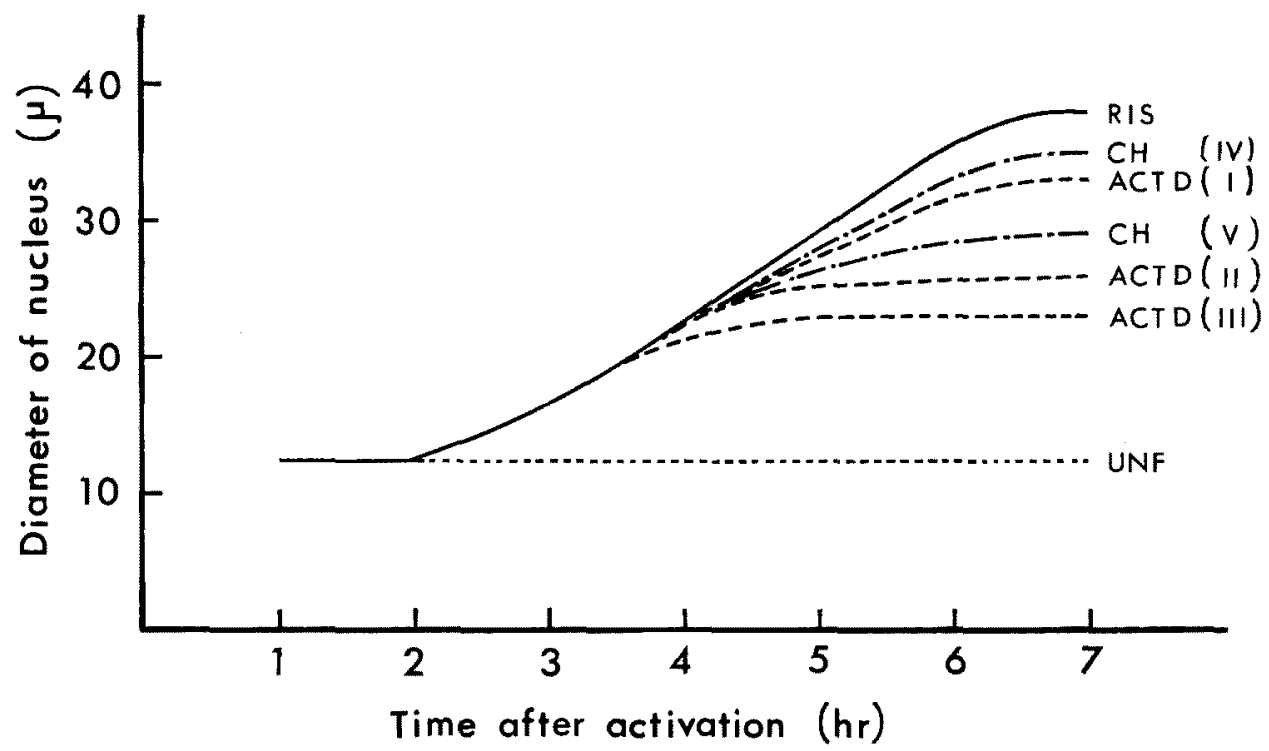

Fig. 10. Changes of nuclear size in the RIS eggs exposed to actinomycin D or cycloheximide $\left(18^{\circ} \mathrm{C}\right)$. -.. -, The eggs exposed to actionmycin D (ACT D) in concentration of 50 (I), 100 (II) and $200 \mu \mathrm{g} / \mathrm{ml}$ (III); - - - the eggs exposed to cycloheximide (CH) in concentration of 200 (IV) and $400 \mu \mathrm{g} / \mathrm{ml}$ (V); - insufficiently activated eggs unexposed to the antibiotics (RIS), as a control. $\cdots \cdots$, unfertilized eggs (UNF).

The effect of actinomycin D and cycloheximide on nuclear changes in the RIS eggs

As a marker of morphological change, the nuclear volume of the RIS egg in different batches was examined at every $1 \mathrm{hr}$ for $7 \mathrm{hr}$. These results are shown in Fig. 10. The antibiotics in high concentration inhibit increase of the nuclear volume about $4 \mathrm{hr}$ after activation. After that, actinomycin $\mathrm{D}$ in concentration of 100 or $200 \mu \mathrm{g} / \mathrm{ml}$ sharply inhibits increase of the nuclear volume, while cycloheximide in 200 or $400 \mu \mathrm{g} / \mathrm{ml}$ shows gradual inhibitory effect.

Fig. 11 represents the nucleus of the egg treated with actinomycin D in high concentration for $6 \mathrm{hr}$. Small dense masses (arrows) scattered and they were difficult to participate in formation of the NDB. Even though NDBs are formed, their matrices are rude appearance lacking some part of the component. In the nucleus of the egg treated with cycloheximide in high concentration for $6 \mathrm{hr}$, spherical NDBs were scarcely formed. Dense materials were loosened and arranged linearly in most cases (Fig. 12).

\section{Pronase digestion}

In order to investigate the components of the NDB in the nucleus of the RIS egg, the treatment with Pronase digestion was carried out. 
With respect to NDBs in these nuclei, it seems that the electron density decreases as a whole, and the outer region is more digested than the inner one (Fig. 13). This suggests that the NDB includes some kinds of protein as one component.
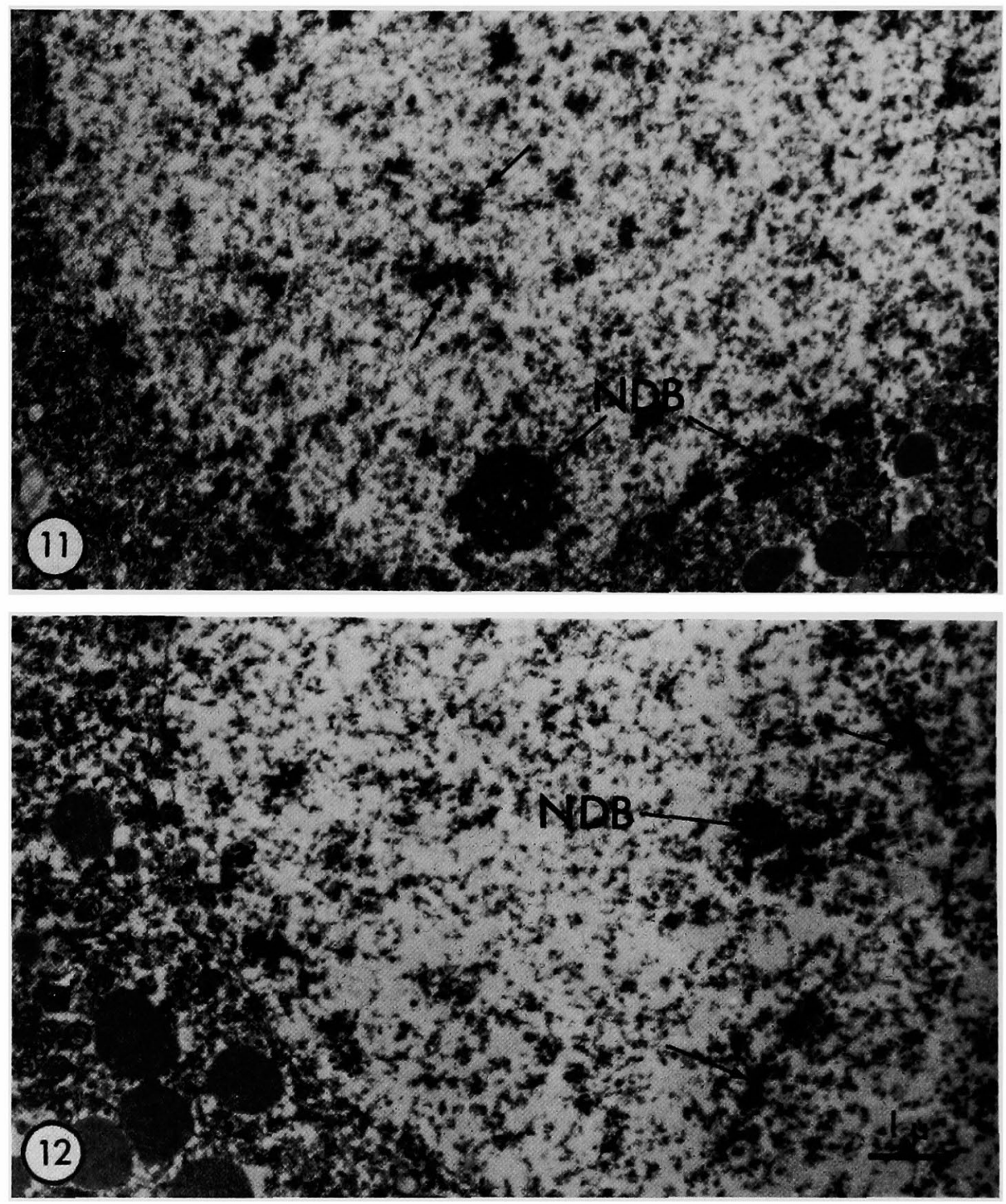

Figs. 11-12. 11, the nucleus of the RIS egg exposed to $200 \mu \mathrm{g} / \mathrm{ml}$ actinomycin D for $6 \mathrm{hr}$. Showing small dense masses scattered (arrows) and the nuclear dense bodies (NDBs) lacked some part of the component. $\times 8,000$. 12 , nucleus of the RIS egg treated with $400 \mu \mathrm{g} / \mathrm{ml}$ cycloheximide for $6 \mathrm{hr}$. Spherical NDBs are scarcely formed. The unaccomplished NDB and linear arrangement of NDBs (arrows) are shown frequently. $\times 8,000$.

\section{Discussion}

In the activated eggs of the sea urchin with single insufficient stimulus, no morphological changes occur. However, a repetition of the insufficient stimulus 
induces some morphological changes a few hours later (Kojima 1969). The noticeable change of the egg is increase of the nuclear volume accompanying with DNA synthesis (Uto 1975). It begins at a few hours after activation and continues for several hours with gradual increase. The nuclear size attains to about 3 times in diameter as compared with that of the unfertilized egg.

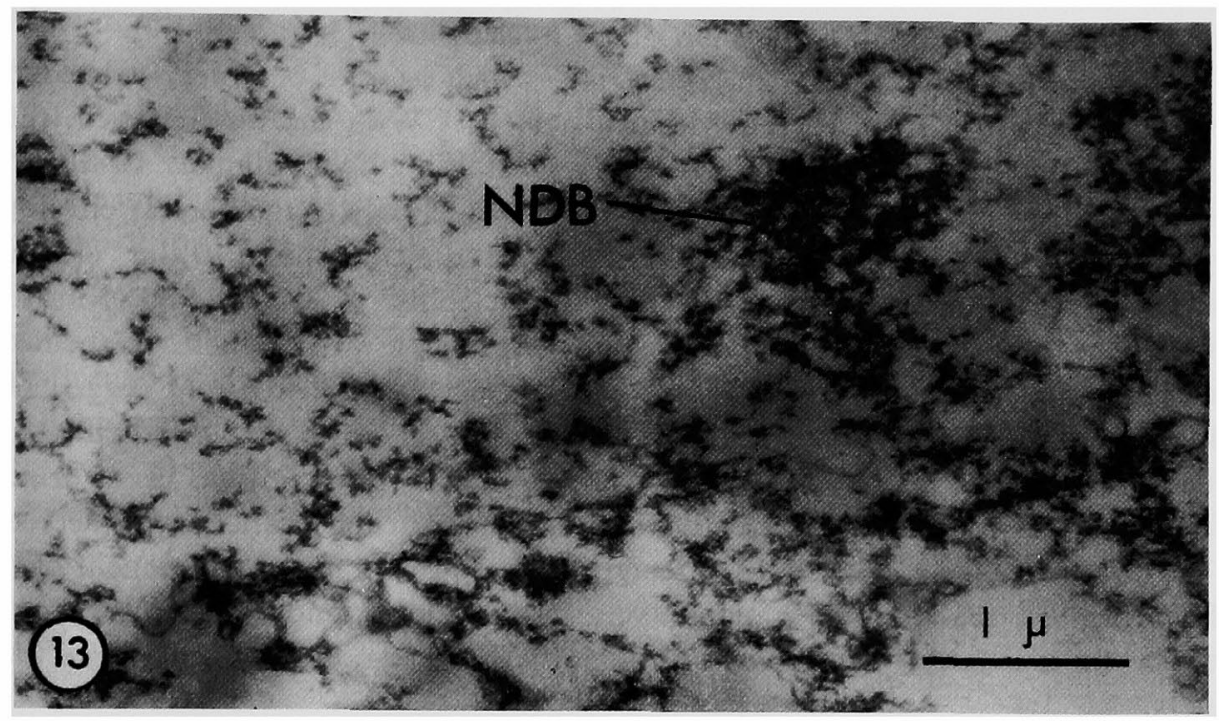

Fig. 13. Nucleus of the RIS egg treated with Pronase for $1 \mathrm{hr}$. As compared with Fig. 7, an electron density of the nuclear dense body (NDB) decreases as a whole, especially in the outer region.

Spherical appearance disintegrates somewhat. $\times 20,000$.

Concerning the relationship between increase of the nuclear volume and DNA synthesis, several investigators have reported until now. Simmel and Karnofsky (1961) observed in the sand dollar eggs that DNA synthesis begins at about the time of nuclear fusion and then nuclear volume increases. By means of autoradiography, Graham et al. (1966) and Gurdon (1967) showed that when the nuclei of embryonic, larval and adult cells of Xenopus laevis were injected into the cytoplasm of unfertilized eggs or oocytes at certain stage of the same species, they did not initiate mitosis but synthesized DNA. Graham et al. (1966) also found that the nuclei of the liver, brain and blood cells injected into Xenopus eggs swell up to 60 times and this swelling of the volume takes place at the same rate as that at which nuclei are induced to synthesize DNA. Graham (1966) demonstrated in another experiment that accessory nuclei which were introduced into the egg during different phase of the cell cycle incorporated ${ }^{3} \mathrm{H}-\mathrm{TdR}$ and entered mitosis synchronously with the resident egg and sperm nuclei. Furthermore, according to him, the nucleus had synthesized DNA in the activated egg by pricking. In both cases, swelling of the nucleus took place accompanying with DNA synthesis. These facts suggest that swelling of the nucleus is induced by activation of DNA synthetic potency in the nucleus.

From the present observation on the insufficiently activated egg with repeated stimulus (RIS egg), it was found that the amount of chromatin thread increases with nuclear swelling, and further ${ }^{3} \mathrm{H}-\mathrm{TdR}$ incorporation takes place on the site of 
chromatin condensation. Based on these results and previous reports (Uto 1975, Uto and Tsukahara 1976), it is supposed that DNA, RNA and protein synthesis in the nucleus arises to some level by insufficient activation.

On the nuclear swelling, two possibilities may be considered as follows. In the first one, the accumulation of the synthesized substances brings higher osmotic pressure in the nucleus than that of the cytoplasm. The second one is that the accumulation results physical expansion of the nucleus itself.

In the RIS eggs, electron dense materials, which seem to be composed of condensed chromatins, are scattered within a nucleus. With the time elapsed, these dense materials gather and migrate gradually, increasing own volume. In the later stage, they grow into the spherical bodies and attach closely to the nuclear envelope.

The NLB observed in the unfertilized egg may be correspond to the "cleavage nucleolus" observed before formation of "true nucleolus" in Arbacia eggs (Karasaki 1968). Similar body has been reported by Harris (1967), which adheres to the inner surface of the nuclear envelope of the unfertilized Stronglyocentrotus egg. This NLB is conceivable to differ from the NDB by reason of its shape, structure and situation. And the NLB is occasionally seen even after the NDB has been formed. Pronase treatment results in disintegration of the spherical appearance and in decrease of the matrix density of the NDB. It suggests that protein is one component of the NDB. By the treatment with actinomycin D or cycloheximide, NDBs are hardly formed. In this case, if NDBs were formed, they lose some components from their matrix.

It has been known that the nucleolus is a compact mass consisting of fibrillar and granular or particulate components. According to Karasaki $(1965,1968)$, both components of the nucleolus in amphibian or sea urchin embryos have clearly different situation each other. However, the structural features of the two components in the NDB are undistinguishable between them in the present result.

From the result of autoradiography of ${ }^{3} \mathrm{H}-\mathrm{TdR}$ incorporation, the neighbourhoods of nuclear envelope seem to be an active site of DNA synthesis, in which chromatin condensation is observed frequently. The silver grains, which represent the ${ }^{3} \mathrm{H}-\mathrm{TdR}$ incorporation, are mainly found on chromatin condensed region but occasionally found also on chromatin dispersed area. Concerning of the site of DNA replication, Comings and Kakefuda (1968) suggested that DNA synthesis in human amnion cells may be initiated at the nuclear envelope. Moreover, Comings and Okada $(1970 \mathrm{a}, \mathrm{b})$ demonstrated that the aggregates of chromatin fiber attach to the annuli of the nuclear envelope, and that chromosomes condense onto the inner surface of the nuclear envelope. Recently, Sparvoli et al. (1976) indicated by autoradiography in meristematic cells of Haplopappus gracilis that DNA replication was observed near or on the nuclear envelope at the late $S$ period. This localized DNA replication is due to a DNA fraction located at the nuclear envelope, which may in part correspond to the constitutive heterochromatin. In the sea urchin, Anthony et al. (1973) isolated a DNA-membrane complex from nuclei of developing embryos and explained that DNA synthesis takes place in this fraction. The complex is relatively absent when DNA synthesis is not occurring, as in the unfertilized egg or during the $\mathrm{G}_{2}$ phase of the cell cycle. 
In the present experiment, it is also suggested that the nuclear envelope may play a role on DNA synthesis. Besides nuclear envelope, dense materials may be an active site of DNA synthesis but the activity decreases in parallel with development of the NDB.

With respect to the characterization of the NDB, unknown points still remain, but the following informations may provide the suggestion of this problem. According to Brachet et al. (1972), in Paracentrotus eggs treated with a mixture of fluorodeoxyuridine (FUdR) and uridine, cleavage nucleoli were enlarged. They have given the possible interpretation for increase in size of the nucleoli: i.e., under this condition, local accumulation of proteins occurs because synthesis of DNA and RNA are inhibited. It has been known that eggs of the amphibia and the sea urchin, certain proteins move from cytoplasm into the nuclei (cf. Loeb et al. 1969, Merriam 1969). On the other hand, Sidebottom and Harris (1969) have indicated in mammalian A9 cells and chick embryonic erythrocytes that nucleoli control the transport of both nucleolar and chromosomal RNA.

From our observation, the following explanation will be possible: when a certain intensity of stimulation are given to the egg surface, cytoplasmic-activating factors are released, and subsequently, the synthetic systems of DNA, RNA and protein are activated in the nucleus. As obtained from the present study, most of the products in these system would not migrate into cytoplasm, and make aggregates within nucleus. The aggregates develop and get to the NDB near the nuclear envelope.

\section{Summary}

When the eggs of the sea urchin, Hemicentrotus pulcherrimus, were activated by 3 times' repetition of the insufficient treatment with butyric acid, DNA was synthesized in the nucleus at the adjacent region of the nuclear envelope and on the chromatin, even though cortical granules did not breakdown. In parallel with this, RNA and protein were also synthesized. In such an egg, several small aggregates of the chromatin are gradually formed in the nucleus and grow to the "nuclear dense body (NDB)" near the nuclear envelope.

Formation of the NDB is suppressed with actinomycin D and cycloheximide in high concentration, and a matrix of the NDB is digested by the treatment with Pronase.

From these results, it was supposed that accumulation of synthesized DNA, RNA and protein in a nucleus brings an increase of osmotic pressure or physical expansion within a nucleus and results in nuclear swelling.

\section{Acknowledgement}

The authors would like to thank Prof. M. Ishikawa of Ehime University and Dr. K. Kojima of Nagoya University for their encouragement during the course of this study, and in the preparation of the manuscript. 


\section{References}

Anthon, A. I., Nauta, R., Gilbert, S., Hobart, P. and Firshein, W. 1973. DNA synthesis in developing sea urchins: role of a DNA-nuclear membrane complex. Nature, New Biology 242: 5-8.

Brachet, J., O'dell, D., Steinert, G. and Tencer, R. 1972. Cleavage nucleoli and ribosomal RNA in sea urchin eggs. Exptl, Cell Res. 73: 463-368.

Comings, D. E. and Kakefuda, T. 1968. Initiation of deoxyribonucleic acid replication at the nuclear membrane in human cells. J. Mol. Biol. 33: 225-229.

- and Okada, T. A. 1970a. Association of chromatin fibers with the annuli of the nuclear membrane. Exptl. Cell Res. 62: 293-302.

- and - 1970b. Condensation of chromosomes onto the nuclear membrane during prophase. Exptl. Cell Res. 63: 471-473.

Graham, C. F. 1966. The regulation of DNA synthesis and mitosis in multinucleate frog eggs. J. Cell Sci. 1 : 363-374.

-, Arms, K. and Gurdon, J. B. 1966. The induction of DNA synthesis by frog egg cytoplasm. Develop. Biol. 14 : 349-381.

Gurdon, J. B. 1967. On the origin and persistence of a cytoplasmic state inducing nuclear DNA synthesis in frogs' eggs. Proc. natn. Acad. Sci. U. S. A. 58: 545-552.

Harris, P. 1967. Nucleolus-like bodies in sea urchin eggs. Amer. Zool. 7: 753.

Karasaki, S. 1965. Electron microscopic examination of the sites of nuclear RNA synthesis during amphibian embryogenesis. J. Cell Biol. 26: 937-958.

- 1968. The ultrastructure and RNA metabolism of nucleoli in early sea urchin embryos. Exptl. Cell Res. 52: 13-26.

Kojima. M. K. 1969. Induction of nuclear change and cleavage by repeated insufficient stimulation with activating reagents in the sea urchin egg. Embryologia 10: 334-342.

Loeb, L. A., Fansler, B., Williams, R. and Mazia, D. 1969. Sea urchin nuclear DNA polymerase. I. Localization in nuclei during rapid DNA synthesis. Exptl. Cell Res. 57: 298-304.

Longo, F. J. and Anderson, E. 1968. The fine structure of pronuclear development and fusion in the sea urchin, Arbacia punctulata. J. Cell Biol. 39: 339-368.

Merriam, R. W. 1969. Movement of cytoplasmic proteins into nuclei induced to enlarge and initiate DNA or RNA synthesis. J. Cell Sci. 5: 333-349.

Nakashima, S. K, and Sugiyama, M. 1969. Incorporation of amino acid into sea urchin eggs stimulated insufficiently with an activating reagent. Develop. Growth and Differ. 11: 115-122.

Sachs, M. I. and Anderson, E. 1970. A cytological study of artificial parthenogenesis in the sea urchin Arbacia punctulata. J. Cell Biol. 47: 140-158.

Sidebottom, E. and Harris, H. 1969. The role of the nucleolus in the transfer RNA from nucleus to cytoplasm. J. Cell Sci. 5: 351-364.

Simmel, E. B. and Karnofsky, D. A. 1961. Observation on the uptake of tritiated thymidine in the pronuclei of fertilized sand dollar embryos. J. Biophys. Biochem. Cytol. 10: 59-65.

Sparvoli, E., Galli, M. G., Mosca, A. and Paris, G. 1976. Localization of DNA replicator sites near the nuclear membrane in plant cells. Exptl. Cell Res. 97: 74-82.

Uto, N. 1975. Further studies on incorporation of ${ }^{3} \mathrm{H}$-thymidine into insufficiently activated eggs of the sea urchin, Hemicentrotus pulcherrimus. Annotat. Zool. Japan. 48: 75-82.

- and Sugiyama, M. 1969. Incorporation of thymidine- ${ }^{3} \mathrm{H}$ into the activated sea urchin egg with special reference to subthreshold stimulation with an activating reagent. Develop. Growth and Differ. 11: 123-129

- and Tsukahara, J. 1976. Studies on the effects of repetition of insufficient activation with butyric acid and benzimidazole in the sea urchin egg. Acta Embryol. Exp. 3: 253-266 